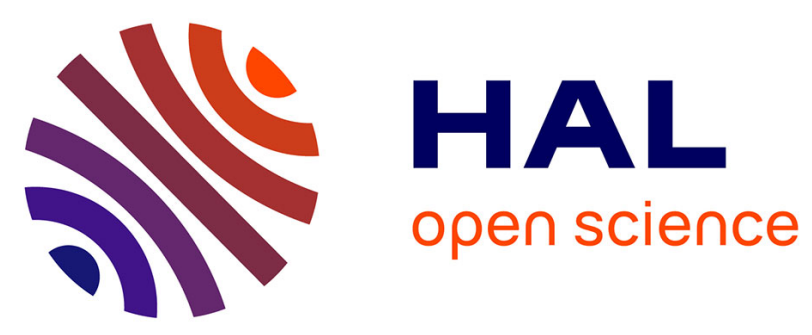

\title{
Gas-Phase Rate Coefficients for the Reaction of 3-hydroxy-2-butanone and 4-hydroxy-2-butanone with $\mathrm{OH}$ and $\mathrm{Cl}$
}

Lyamine Messaadia, Gisèle El Dib, Maria Lendar, Mathieu Cazaunau, Estelle Roth, Azeddine Ferhati, Abdelwahid S Mellouki, Abdelkhaleq Chakira

\section{To cite this version:}

Lyamine Messaadia, Gisèle El Dib, Maria Lendar, Mathieu Cazaunau, Estelle Roth, et al.. Gas-Phase Rate Coefficients for the Reaction of 3-hydroxy-2-butanone and 4-hydroxy-2-butanone with $\mathrm{OH}$ and Cl. Atmospheric environment, 2013, 77, pp.951-958. 10.1016/j.atmosenv.2013.06.028 . hal-00841336

\section{HAL Id: hal-00841336 \\ https://hal-univ-rennes1.archives-ouvertes.fr/hal-00841336}

Submitted on 4 Jul 2013

HAL is a multi-disciplinary open access archive for the deposit and dissemination of scientific research documents, whether they are published or not. The documents may come from teaching and research institutions in France or abroad, or from public or private research centers.
L'archive ouverte pluridisciplinaire HAL, est destinée au dépôt et à la diffusion de documents scientifiques de niveau recherche, publiés ou non, émanant des établissements d'enseignement et de recherche français ou étrangers, des laboratoires publics ou privés. 


\title{
Gas-Phase Rate Coefficients for the Reaction of 3-hydroxy-2-butanone and 4-hydroxy-2-
} butanone with $\mathrm{OH}$ and $\mathrm{Cl}$

\author{
L. Messaadia ${ }^{\text {a,b }}$, G. El Dib ${ }^{\text {c }}$, M. Lendar ${ }^{\text {d }}$, M. Cazaunau ${ }^{\text {d }}$, E. Roth ${ }^{\text {a }}$, A. Ferhati ${ }^{\text {b }}$, \\ A. Mellouki ${ }^{\text {d }}$ and A. Chakir ${ }^{\text {a,* }}$ \\ ${ }^{a}$ Université de Reims, Laboratoire GSMA-UMR 6089 CNRS, Campus Moulin de la Housse, BP 1039, \\ 51687 Reims cedex 02, France \\ ${ }^{\mathrm{b}}$ Laboratoire LCCE, Faculté des sciences, Université de Batna, rue Boukhlouf El Hadi 05000 Batna, Algeria \\ ${ }^{\mathrm{c}}$ Département de Physique Moléculaire, Institut de Physique de Rennes, UMR 6251 du CNRS - Université \\ de Rennes 1, Bat. 11c, Campus de Beaulieu, 35042 Rennes Cedex, France \\ ${ }^{\mathrm{d}}$ ICARE-CNRS/OSUC, IC Avenue de la recherche scientifique 45071, Orléans Cedex 02, France
}

\section{ABSTRACT}

The reactions of the $\mathrm{OH}$ radicals and the $\mathrm{Cl}$ atoms with 3-hydroxy 2-butanone $(3 \mathrm{H} 2 \mathrm{~B})$ and 4-hydroxy 2-butanone (4H2B) were investigated in the gas-phase using relative rate method. The kinetic study on the OH-reactions was carried out using a Pyrex atmospheric chamber at 600-760 Torr of purified air. The temperature ranges were $298-338 \mathrm{~K}$ for $3 \mathrm{H} 2 \mathrm{~B}$ and $278-333$ $\mathrm{K}$ for $4 \mathrm{H} 2 \mathrm{~B}$. A slight negative dependence of the rate coefficients behavior was observed and the Arrhenius expressions obtained are (in $\mathrm{cm}^{3}$ molecule $\left.{ }^{-1} \mathrm{~s}^{-1}\right): \mathrm{k}_{3 \mathrm{H} 2 \mathrm{~B}(\mathrm{OH})}=(1.25 \pm 0.20) \times$ $10^{-12} \exp (612 \pm 50 / \mathrm{T})$ and $\mathrm{k}_{4 \mathrm{HB}(\mathrm{OH})}=(7.50 \pm 2.0) \times 10^{-12} \exp (196 \pm 20 / \mathrm{T})$. Rate coefficients for the gas-phase reactions of $\mathrm{Cl}$ atoms with $3 \mathrm{H} 2 \mathrm{~B}$ and $4 \mathrm{H} 2 \mathrm{~B}$ were measured using an atmospheric simulation chamber made of Teflon at $298 \pm 3 \mathrm{~K}$ and 760 Torr. The obtained rate coefficients (in $\mathrm{cm}^{3}$ molecule $\mathrm{s}^{-1} \mathrm{~s}^{-1}$ ) were $(4.90 \pm 0.45) \times 10^{-11}$ and $(1.45 \pm 0.15) \times 10^{-10}$ for $3 \mathrm{H} 2 \mathrm{~B}$ and $4 \mathrm{H} 2 \mathrm{~B}$, respectively. The obtained data are presented, compared to those reported in the literature and the reactivity trends discussed. The estimated tropospheric lifetimes obtained in this work suggest that once emitted into the atmosphere, $3 \mathrm{H} 2 \mathrm{~B}$ and $4 \mathrm{H} 2 \mathrm{~B}$ will be oxidized near the emission sources.

\section{Keywords}

$\mathrm{OH}$ radicals, $\mathrm{Cl}$ atoms, kinetics, hydroxyketones, Arrhenius expression, Atmospheric lifetimes

\footnotetext{
* Corresponding author : E mail address : abdel.chakir@univ-reims.fr
} 


\section{Introduction}

Hydroxycarbonyls, a variety of multi-functional Volatile Organic Compounds (VOCs), are used in a number of industrial sectors namely in food (Rivas et al., 2003), chemicals and pharmaceuticals synthesis (Ichikawa et al., 2005). Furthermore, they are formed in situ in the atmosphere through the oxidation of anthropogenically and naturally emitted VOCs such as alkanes, alkenes, alkynes, oxygenated and carbonyl compounds. For example, the photooxidation of diols and branched alcohols leads to the formation of 2-hydroxybutanone and hydroxycarbonyls at 60\% and 20\% yields, respectively (Bethel el al., 2001; Bethel el al, 2003). $\beta$-hydroxycarbonyls are mainly produced from the $\mathrm{OH}$-initiated oxidation of alkenes (Atkinson, 1997a) and 1,4-hydroxycarbonyls can be formed during the oxidation of alkanes (Aschmann et al., 2000; Atkinson et al., 2008).

The release of these compounds in the atmosphere may contribute to the formation of other secondary pollutants such as tropospheric ozone and photochemical smog precursors. In common with other carbonyl compounds, the most important atmospheric sinks of hydroxycarbonyls not containing $\mathrm{C}=\mathrm{C}$ bonds are by daytime reaction with $\mathrm{OH}$ and/or by photolysis. The oxidation of these compounds can affect the atmospheric chemistry of radicals and the oxidizing capacity of the atmosphere.

Despite the importance of hydroxyketones in atmospheric chemistry and their effect on the production of atmospheric free radicals and photooxidants, very little information exists about the atmospheric fate of longer chain $\mathrm{C}_{4}$-hydroxyketones (Aschmann et al., 2000; Baker et al., 2004; El Dib et al., 2013; Messaadia et al., 2012). The atmospheric degradation of $\mathrm{C}_{4^{-}}$ hydroxyketones by reactions with oxidants has been studied by Aschmann et al. (2000a), Baker et al. (2004) and El Dib et al.( 2013). In the first two studies, the gas phase kinetics of a series of $\mathrm{C}_{4}$ - hydroxyketones was investigated at room temperature and atmospheric pressure using a relative technique. Aschmann et al. (2000a) have studied the reaction of a series of hydroxyketones including four $\mathrm{C}_{4}$-hydroxyketones, with $\mathrm{OH}, \mathrm{NO}_{3}$ and $\mathrm{O}_{3}$. The obtained results indicated that the gas-phase reaction with the $\mathrm{OH}$ radical dominates over reactions with $\mathrm{NO}_{3}$ and that no reactions were observed with $\mathrm{O}_{3}$. In the study carried out by Baker et al. (2004) two $\mathrm{C}_{4}$ - hydroxyketones (1-hydroxy 2-butanone and 4-hydroxy 2butanone) have been identified as products of the reactions of hydroxyaldehydes with $\mathrm{OH}$.

66 The rate coefficient of the reaction of these hydroxyketones with $\mathrm{OH}$ has been measured as 
agreement with the previous study carried out by Aschmann et al. (2000a). However, the rate coefficient obtained by these authors for 4-hydroxy 2-butanone was $42 \%$ higher than that obtained by Aschmann et al. (2000a). In the study carried out by El Dib et al. (2013), the reaction of 4-hydroxy 2-butanone with $\mathrm{OH}$ radicals was investigated using the pulsed laser photolysis - laser induced fluorescence technique at room temperature and over the pressure range of 10 to 330 Torr in He and air as diluents gases. An absolute rate coefficient of (4.8 \pm 1.2) $\times 10^{-12} \mathrm{~cm}^{3}$ molecule $\mathrm{s}^{-1}$ was determined which is lower than those measured by Aschmann et al. (2000a) and Baker et al. (2004) by factors of $40 \%$ and 65\%, respectively.

The study of the gas-phase atmospheric chemistry of $3 \mathrm{H} 2 \mathrm{~B}$ is presently limited to only one investigation carried out by Aschmann et al. (2000a) at $294 \pm 2 \mathrm{~K}$ and 740 Torr total pressure of purified air using a relative rate technique.

Upper limits of the UV photolysis rates of a series of hydroxyketones have been calculated by Messaadia et al. (2012) using a quantum yield of unity assuming that photolysis might be a loss process for these species. These previous studies showed that the UV photolysis and the gas-phase reaction with the $\mathrm{OH}$ radicals are expected to be the dominant tropospheric chemical loss processes for these species. To our knowledge, no data on the reaction of these species with $\mathrm{Cl}$ atoms exist in the literature. Thus, to enrich kinetic databases regarding these compounds, we have undertaken the present kinetic study.

The purpose of this work is to study the kinetics of two $\mathrm{C}_{4}$ - hydroxyketones with $\mathrm{OH}$ radicals as a function of temperature and with $\mathrm{Cl}$ atoms at room temperature. The studied compounds were: 3-hydroxy 2-butanone $\mathrm{CH}_{3} \mathrm{C}(\mathrm{O}) \mathrm{CH}(\mathrm{OH}) \mathrm{CH}_{3}(3 \mathrm{H} 2 \mathrm{~B})$ where the $\mathrm{OH}$ group is in the $\alpha$ position, 4-hydroxy 2-butanone $\mathrm{CH}_{3} \mathrm{C}(\mathrm{O}) \mathrm{CH}_{2} \mathrm{CH}_{2} \mathrm{OH}(4 \mathrm{H} 2 \mathrm{~B})$, where the $\mathrm{OH}$ group is in the $\beta$ position.

The experiments were conducted using two different experimental systems. The reactions with $\mathrm{OH}$ were investigated at GSMA-Reims over the pressure range of 600 to 760 Torr and the temperature ranges of $298-338 \mathrm{~K}$ and $278-333 \mathrm{~K}$ for $3 \mathrm{H} 2 \mathrm{~B}$ and $4 \mathrm{H} 2 \mathrm{~B}$, respectively. The reactions with $\mathrm{Cl}$ atoms were conducted at ICARE-Orléans at $298 \pm 3 \mathrm{~K}$ and 760 Torr of purified air.

This work provides the first kinetic data for the reactions of $3 \mathrm{H} 2 \mathrm{~B}$ and $4 \mathrm{H} 2 \mathrm{~B}$ with $\mathrm{OH}$ as a function of temperature and the first data for the reaction of these species with $\mathrm{Cl}$ atoms. The data obtained in this work were used to estimate the effective lifetimes in the troposphere of the studied compounds. The obtained data are presented and compared to those reported in the 
100 literature for the studied species and for other hydroxyketones. In addition, the results are 101 discussed in terms of the temperature and the hydroxyl group position effects.

\section{Experimental section}

105

106

\subsection{Reactions with $\mathrm{OH}$ radicals}

The reactions of $3 \mathrm{H} 2 \mathrm{~B}$ and $4 \mathrm{H} 2 \mathrm{~B}$ with $\mathrm{OH}$ radicals were studied using a simulation chamber coupled to a FTIR spectrometer at GSMA-Reims. The set up used is shown in Fig.1. The reactor is a triple-jacket Pyrex cell (length $2 \mathrm{~m}$, internal diameter $20 \mathrm{~cm}$ ) equipped with a multiple reflection system. The first two outer layers delimit a vacuum envelope by using a pump in order to isolate the whole system from its surroundings. The temperature regulation is provided by a fluid (water or ethanol) circulating between the inner wall and the second jacket using a thermostat (Julabo FPW 90). The working temperature range of the thermostat was -between -40 and $+100{ }^{\circ} \mathrm{C}$. Platinum resistance temperature sensors were used to provide continuous and simultaneous temperature readings. Meanwhile, the pressure inside the cell was measured by $(0-1000)$ Torr MKS Baratron capacitance manometers.

The multiple reflection system in the inner chamber is a White cell equipped with three gold mirrors located at both ends of the cell. These mirrors were used to regulate the path length of the probe beam by controlling the number of reflections as detailed below. $24 \mathrm{UV}$ lamps providing radiation of wavelength varying between 300 and $400 \mathrm{~nm}$ are symmetrically placed around the reactor to yield a homogeneous photolysis of the reactants. An Equinox 55 FT-IR spectrometer provided by Bruker was used to monitor the concentration of the reactants and reference compounds. The spectral resolution was in the range of $2-0.5 \mathrm{~cm}^{-1}$ in the spectral range $600-4000 \mathrm{~cm}^{-1}$.

$\mathrm{OH}$ radicals were generated by the photolysis of nitrous acid which was produced in a drop-wise by the addition of $10 \%$ of sulphuric acid to a solution of $0.2 \mathrm{M}$ of sodium nitrite. A small flow of nitrogen gas was used to carry the generated nitrous acid into the reactor. For these experiments, benzaldehyde was used as reference compound.

The experimental conditions are summarized in Table 1 used during these measurements. The kinetic studies were performed at different temperatures depending on the vapor pressures of the studied compounds (less than 0.1 Torr for $3 \mathrm{H} 2 \mathrm{~B}$ as measured during our experiments and in the range of $0.38-11.3$ Torr for $4 \mathrm{H} 2 \mathrm{~B}$ in the temperature range $278-333 \mathrm{~K}$ as reported by El Dib et al. (2013)). 
134 The reactions of $3 \mathrm{H} 2 \mathrm{~B}$ and $4 \mathrm{H} 2 \mathrm{~B}$ with $\mathrm{Cl}$ atoms were studied using a simulation chamber 135 coupled to a GC-FID at ICARE-Orléans. The experimental procedure has been presented in 136 details by Thevenet et al. (2000), therefore, it will be only described briefly here. Experiments 137 were carried out in a 120 to $180 \mathrm{~L}$ Teflon bag at room temperature and atmospheric pressure. 138 The Teflon bag was surrounded by fluorescent black lamps, providing suitable UV radiation 139 with a maximum around $360 \mathrm{~nm}$ and positioned in a wooden box with the internal faces 140 covered with aluminum foil. Measured amounts of reagents were flushed from calibrated 141 bulbs into the Teflon bag through a stream of ultra pure air. The reactor was then filled to its 142 full capacity at atmospheric pressure with ultra pure air. Photolysis of $\mathrm{Cl}_{2}$ at $300-400 \mathrm{~nm}$ was 143 used as the source of $\mathrm{Cl}$ atoms. A gas chromatograph equipped with flame ionization detector 144 (GC-FID, CP-3800 Varian) was used for the quantitative analysis of the reactants. 145 Chromatographic separation was achieved by using a DB-1 capillary column (J\&W 146 Scientific. $30 \mathrm{~m} .0 .25 \mathrm{~nm}$ id. $5 \mu \mathrm{m}$ Film). The column was operated between 333 and $353 \mathrm{~K}$ 147 and helium was used as carrier gas. The kinetics started with the lighting of the lamps. The experimental conditions were varied in order to validate our measurements. In fact, the number of lamps was varied from 2 to 6 depending of the reactivity of the studied compound. The concentrations of the studied hydroxyketone and the reference compounds were chosen according to the ratio of their reactivities with chlorine atoms. The introduced reagent quantities (in molecule $\mathrm{cm}^{-3}$ ) and the experimental conditions are summarized in Table 2.

153 Four different reference compounds were used: ethane $\mathrm{C}_{2} \mathrm{H}_{6}$, cyclohexane $\mathrm{C}_{6} \mathrm{H}_{12}$, dioxolane $154 \mathrm{C}_{3} \mathrm{H}_{6} \mathrm{O}_{2}$ and ethyl formate $\mathrm{C}_{3} \mathrm{H}_{6} \mathrm{O}_{2}$..

155 It is to be noted that the reference compounds were chosen in such a way that their rate coefficients are well defined in the literature. In addition to these constraints, the reference compound should have a FTIR spectrum and a retention time (for FTIR and GC FID, respectively) sufficiently different from that of the investigated hydroxyketones.

Before starting the kinetic study with $\mathrm{OH}$ and $\mathrm{Cl}$, two tests were carried out to check:

- that in the absence of the radical precursor, the studied hydroxyketones are not photolysed in the spectral range used to generate $\mathrm{OH}(\mathrm{Cl})$. The tests showed that the variation of the concentrations of the studied compounds was lower than $2 \%$.

- the stability of the gas mixture concentrations in the absence of irradiation. This test showed a good stability and a negligible effect of the losses on the walls for measurements above $298 \mathrm{~K}$ as discussed in Section "Results". 
The measurements were performed in purified air provided by Air Liquide (> 99.9999\%). The used reagents were obtained from the following sources: $\mathrm{C}_{2} \mathrm{H}_{6}(99.999 \%)$ and $\mathrm{Cl}_{2}$ (99.5\%) provided by Air Liquide, $\mathrm{C}_{6} \mathrm{H}_{5} \mathrm{CHO}$ (99.5\%), cyclohexane (99.5\%), dioxolane (99\%) and ethyl formate (97\%), 3-hydroxy 2-butanone (99\%), 4-hydroxy 2-butanone (95\%) provided from Aldrich. They were further purified by repeated freeze-pump-thaw cycles before use.

\section{Results}

The rate coefficients of the following reactions have been measured:

The rate coefficients of the reactions with the reference compounds used in this study are (in $\mathrm{cm}^{3}$ molecule $\left.\mathrm{s}^{-1}\right): \mathrm{k}_{(\text {benzaldehyde }+\mathrm{OH}))}=\left(5.33 \times 10^{-12} \exp ((2020 \pm 710) / \mathrm{RT})\right.$ (Semadeni et al., $1994) ; \mathrm{k}_{(\mathrm{ethane}+\mathrm{Cl})}=(4.80 \pm 1) \times 10^{-11}$ (Anderson et al., 2007); $\mathrm{k}_{(\text {cyclohexane }+\mathrm{Cl})}=(3.83 \pm 0.12) \times$ $10^{-10}$ (Anderson et al., 2007) $; \mathrm{k}_{(\text {dioxolane }+\mathrm{Cl})}=(1.67 \pm 0.09) \times 10^{-10}$ (Sauer et al., 1999); $\mathrm{k}_{(\text {ethyl-formate }+\mathrm{Cl})}=(1.34 \pm 0.15) \times 10^{-11}$ (Notario et al., 1998).

In relative kinetic experiments the following reactions take place:

$$
\text { Oxidant }(\mathrm{OH} \text { or } \mathrm{Cl})+\text { hydroxyketone } \rightarrow \text { products }
$$

$$
\text { Oxidant }(\mathrm{OH} \text { or } \mathrm{Cl})+\text { reference } \rightarrow \text { products }
$$

As mentioned above, no loss on the wall or by photolysis was observed during the tests prior to the measurements at temperatures above $298 \mathrm{~K}$. Therefore, the reaction with the oxidant

$189(\mathrm{OH}$ or $\mathrm{Cl})$ is the only sink for the hydroxyketone and the reference compounds. Hence, it can 190 be shown that:

$$
\ln \frac{[\text { hydroxyketone }]_{0}}{[\text { hydroxyketone }]_{t}}=\frac{k_{\text {hydroxykeone }}}{k_{\text {ref }}} \times \frac{[\text { ref }]_{0}}{[\text { ref }]_{t}}
$$

193 reagents before irradiation and at time t respectively and $k_{\text {hydroxykeone }}$ is the rate coefficient of 194 the reaction of the studied reagents with the oxidant $(\mathrm{OH}$ or $\mathrm{Cl}), k_{\text {ref }}$ is the rate coefficient of 195 the reference compounds with the oxidant $(\mathrm{OH}$ or $\mathrm{Cl})$. 
The plot of $\ln \frac{[\text { hydroxyketone }]_{0}}{[\text { hydroxyketone }]_{t}}$ vs. $\ln \frac{[\text { ref }]_{0}}{[\text { ref }]_{t}}$ should be a straight line that pass through

197 the origin with a slope equal to $\frac{k_{\text {hydroxykeone }}}{k_{\text {ref }}}$.

The obtained data are presented in the form $\ln \frac{[\text { hydroxyketone }]_{0}}{[\text { hydroxyketone }]_{t}}$ vs. $\ln \frac{[\text { ref }]_{0}}{[\text { ref }]_{t}}$ as can be

seen in Fig. 2a - 2b and Fig. 3a - 3b for the reactions with $\mathrm{OH}$ and $\mathrm{Cl}$ of $3 \mathrm{H} 2 \mathrm{~B}$ and 4H2B, respectively.

A slight decrease in the $4 \mathrm{H} 2 \mathrm{~B}$ concentration was observed however at $278 \mathrm{~K}$ in absence of the oxidant indicating a loss on the chamber wall which might be due to the low vapor pressure of $4 \mathrm{H} 2 \mathrm{~B}(\approx 0.4$ Torr at $278 \mathrm{~K}$, (El Dib et al., 2013)). Therefore, the rate coefficient of the reaction of $4 \mathrm{H} 2 \mathrm{~B}$ with $\mathrm{OH}$ at $278 \mathrm{~K}$ was extracted using the following relation:

$$
\frac{1}{\left(t-t_{0}\right)} \ln \frac{[4 H 2 B] \mathrm{t}_{0}}{[4 H 2 B]_{\mathrm{t}}}=\frac{\mathrm{k}_{4 \mathrm{H}_{2} \mathrm{~B}(\mathrm{OH})}}{\mathrm{k}_{\mathrm{ref}}} \cdot \frac{1}{\left(t-t_{0}\right)} \cdot \ln \frac{[R e f] \mathrm{t}_{0}}{[R e f]_{\mathrm{t}}}+\left(k^{\prime}-\frac{\mathrm{k}_{4 \mathrm{H}_{2} \mathrm{~B}(\mathrm{OH})}}{\mathrm{k}_{\mathrm{ref}}} \mathrm{k}_{\mathrm{ref}}^{*}\right)
$$

where $[4 \mathrm{H} 2 \mathrm{~B}]_{0}$ and $[\mathrm{Ref}]_{0}$ are the initial concentrations of $4 \mathrm{H} 2 \mathrm{~B}$ and the reference compound at time $\mathrm{t}_{0}$, respectively; $[4 \mathrm{H} 2 \mathrm{~B}]_{\mathrm{t}}$ and $[\mathrm{ref}]_{\mathrm{t}}$ are the concentrations of $4 \mathrm{H} 2 \mathrm{~B}$ and the reference compound at time t. $\mathrm{k}_{4 \mathrm{H} 2 \mathrm{~B}(\mathrm{OH})}$ and $\mathrm{k}_{\text {ref }}$ are the rate coefficients of the reactions of $\mathrm{OH}$ with $4 \mathrm{H} 2 \mathrm{~B}$ and the reference compound. k' and $\mathrm{k}^{\prime}$ ref represent the pseudo-first order rate coefficients of the secondary reactions of both compounds, such as wall losses. Fig. 2c represents the plots of $\ln \left(\left[4 \mathrm{H} 2 \mathrm{~B}_{\mathrm{t} 0} /[4 \mathrm{H} 2 \mathrm{~B}]_{\mathrm{t}}\right) /\left(\mathrm{t}-\mathrm{t}_{0}\right)\right.$ vs $\ln \left([\operatorname{Ref}]_{\mathrm{t} 0} /[\operatorname{Ref}]_{\mathrm{t}}\right) /\left(\mathrm{t}-\mathrm{t}_{0}\right)$ where the consumption of $4 \mathrm{H} 2 \mathrm{~B}$ due to the loss on the wall is taken into account.

In all figures, good linearity is observed with a correlation coefficient greater than $92 \%$. The rate coefficients obtained are summarized in Table 3. The Arrhenius equations for the reactions with $\mathrm{OH}$ and the average rate coefficients for the reactions with $\mathrm{Cl}$ atoms were as follows (in $\mathrm{cm}^{3}$ molecule $\mathrm{s}^{-1}$ ):

$$
\begin{gathered}
\mathrm{k}_{3 \mathrm{H} 2 \mathrm{~B}(\mathrm{OH})}=(1.25 \pm 0.20) \times 10^{-12} \exp (612 \pm 50 / \mathrm{T}) \\
\mathrm{k}_{4 \mathrm{H} 2 \mathrm{~B}(\mathrm{OH})}=(7.5 \pm 2.0) \times 10^{-12} \exp (196 \pm 20 / \mathrm{T}) \\
\mathrm{k}_{3 \mathrm{H} 2 \mathrm{~B}(\mathrm{Cl})}=(4.90 \pm 0.45) \times 10^{-11} \\
\mathrm{k}_{4 \mathrm{H} 2 \mathrm{~B}(\mathrm{Cl})}=(1.45 \pm 0.15) \times 10^{-10}
\end{gathered}
$$

The results given above are derived from the average of 3 to 6 independent measurements. For each point in Fig.2-3, the error bar indicates the systematic errors due to uncertainties on the experimental conditions as described in section "Error analysis". The overall uncertainties 
on the rate coefficient values incorporate both statistical errors due to the fit and systematic errors due to experimental conditions. This point will be discussed in the following section.

\section{Discussion}

\subsection{Error analysis}

230 The overall error in the rate coefficient values reported in this work arises from two different types of error: (i) Random errors are caused by unknown and unpredictable changes in the experiment that mainly occur in the measuring instruments. These errors are reduced by averaging multiple experiments and their contribution is smaller than that of systematic errors. (ii) Systematic errors are due to methodological, instrumental and personal mistakes. In this work, the errors on the measured rate coefficients errors are determined using the error propagation method according to equation III:

$$
\Delta k_{\text {hydroxykeone }}=k_{\text {hydroxykeone }} \times\left[\left(\frac{\Delta k_{\text {ref }}}{k_{\text {ref }}}\right)^{2}+\left[\frac{\Delta\left(\frac{k_{\text {hydroxykeone }}}{k_{\text {ref }}}\right)}{\frac{k_{\text {hydroxykeone }}}{k_{\text {ref }}}}\right]^{2}\right]^{1 / 2}
$$

$$
\text { Where }\left(\frac{\Delta k_{\text {ref }}}{k_{\text {ref }}}\right) \text { and }\left(\Delta\left(\frac{k_{\text {hydroxykeone }}}{k_{\text {ref }}}\right) /\left(\frac{k_{\text {hydroxykeone }}}{k_{\text {ref }}}\right)\right) \text { are the relative errors on } k_{\text {ref }} \text { and }
$$
$\frac{k_{\text {hydroxykeone }}}{k_{\text {ref }}}$, respectively.

the errors sources mainly come from:

- the determination of $k_{r e f}$ : This error found in the literature, varies from 3 to $20 \%$ according to the used reference compound.

- the determination of the ratio $\frac{k_{\text {hydroxykeone }}}{k_{\text {ref }}}$. This parameter represents the slope of the plot of $\ln \frac{[\text { Hydroxyketone }]_{0}}{[\text { Hydroxyketone }]_{t}}$ vs. $\ln \frac{[\text { ref }]_{0}}{[\text { ref }]_{t}}$.

This slope is determined directly from experimental data points. The error of this parameter is mainly influenced by the analytical technique used to monitor the reagents' concentrations. In fact, for the reaction with $\mathrm{OH}$ radicals, the uncertainty on the slope $\mathrm{k}_{\text {hydroxyketone }} / \mathrm{k}_{\text {ref }}$ depends mainly on the errors related to the measurements of the areas of spectroscopic peaks, corresponding to both the analyte and the reference compound. In order to minimize this error 
a large number of spectra (30 to 70) were collected at different time intervals for each

251 experiment. For the reaction with $\mathrm{Cl}$ atoms, the uncertainty on the slope is related to the areas of the chromatograms peaks corresponding to the reagents. In order to minimize this uncertainty, several preliminary tests were carried out. This enabled us to optimize the experimental conditions such as the column temperature and the selection of the reference compound and to have relatively intense chromatograms peaks. Moreover, for each experiment, a large number of samples (20-40) were analyzed in order to minimize the error on the determination of the slope.

\subsection{Comparison with previous studies}

The study of the gas-phase atmospheric chemistry of $3 \mathrm{H} 2 \mathrm{~B}$ with $\mathrm{OH}$ radicals is presently limited to only one investigation carried out by Aschmann et al. (2000a) at $294 \pm 2$ $\mathrm{K}$ and 740 Torr total pressure of purified air using a relative rate method. The rate coefficient obtained by these authors $(1.03 \pm 0.22) \times 10^{-11}$ in $\mathrm{cm}^{3}$ molecule $\mathrm{s}^{-1}$ was determined by using n-octane as reference compound. Our value is in good agreement with this determination with a difference less than $5 \%$.

The room temperature rate coefficient for the reaction of $4 \mathrm{H} 2 \mathrm{~B}$ with $\mathrm{OH}$ radicals has been reported in three previous studies (Aschmann et al., 2000a; Baker et al., 2004; El Dib et al., 2013). Aschmann et al. (2000a) measured a rate coefficient of $(8.1 \pm 1.8) \times 10^{-12} \mathrm{~cm}^{3}$ molecule $\mathrm{s}^{-1} \mathrm{~s}^{-1}$ whereas Baker et al. (2004) obtained a larger rate coefficient of $(13.9 \pm 2.8)$ $\times 10^{-12} \mathrm{~cm}^{3}$ molecule $\mathrm{e}^{-1} \mathrm{~s}^{-1}$. Both studies have been conducted at 740 Torr and $296 \mathrm{~K}$ in purified air using a relative method. The rate coefficient obtained in the present work is found to be very close to that reported by Baker et al. (2004) $(\approx 7 \%)$ and larger than that measured by Aschmann et al. (2000a) by a factor of $38 \%$.

In the study carried out by El Dib et al. (2013) using an absolute method, a rate coefficient of $(4.8 \pm 1.2) \times 10^{-12} \mathrm{~cm}^{3}$ molecule ${ }^{-1} \mathrm{~s}^{-1}$ is reported. This value is lower than our value by a factor of $63 \%$. The accuracy of the results obtained in absolute methods might be limited by the concentration measurement. In fact, a potential source of discrepancy could be an overestimation of the $4 \mathrm{H} 2 \mathrm{~B}$ concentration in the experiment carried out by El Dib et al. (2013) which would result in an underestimation of the rate coefficient. However, as stated by the authors, no loss of $4 \mathrm{H} 2 \mathrm{~B}$ has been observed during its introduction into the main reactor due either to possible loss to the wall or to the photodissociation. In addition, the kinetics of 4- hydroxy 4-methyl 2 -pentanone (4H4M2P) with $\mathrm{OH}$ has been carried out recently by these authors at $298 \mathrm{~K}$ in the gas phase using the same technique as that used for $4 \mathrm{H} 2 \mathrm{~B}$. 4H4M2P 
has a vapor pressure very close to that of $4 \mathrm{H} 2 \mathrm{~B}$. The obtained value was found to be in good agreement with the three values reported in the literature and determined by using a relative method. In light of the above explanation, at this time, we cannot identify any potential systematic error that might be the source of this discrepancy with the absolute value reported by El Dib et al. (2013).

Until now, no kinetic data are reported in the literature for the reaction of $3 \mathrm{H} 2 \mathrm{~B}$ and $4 \mathrm{H} 2 \mathrm{~B}$ with $\mathrm{OH}$ radicals as a function of temperature.

Our experimental values were compared to calculated values obtained by using (AOPWIN,2000) v.1.92 based on SAR calculations. A rate coefficient of $5.9 \times 10^{-12} \mathrm{~cm}^{3}$ molecule $\mathrm{s}^{-1} \mathrm{~s}^{-1}$ was obtained for the reaction of $3 \mathrm{H} 2 \mathrm{~B}$ with $\mathrm{OH}$. This value is lower than our experimental value by a factor of $44 \%$. The calculated rate coefficient $\left(1.39 \times 10^{-11} \mathrm{~cm}^{3}\right.$ molecule $\mathrm{s}^{-1} \mathrm{~s}^{-1}$ ) for the reaction of $4 \mathrm{H} 2 \mathrm{~B}$ with $\mathrm{OH}$ was however in very good agreement with our measurement.

Up to now, there is no published study on the reaction of chlorine atoms with $3 \mathrm{H} 2 \mathrm{~B}$ and $4 \mathrm{H} 2 \mathrm{~B}$.

\subsection{Temperature effect}

In the temperature range explored in this work, a slight variation of the rate coefficient with the temperature was observed for the reactions of $\mathrm{OH}$ with $3 \mathrm{H} 2 \mathrm{~B}$ and $4 \mathrm{H} 2 \mathrm{~B}$. With nonlinear least-squares fitting routine, the following Arrhenius expression is obtained $\left(\mathrm{cm}^{3}\right.$ molécule $\left.\mathrm{s}^{-1} \mathrm{~s}^{-1}\right)$ :

$$
\begin{aligned}
& \mathrm{k}_{3 \mathrm{H} 2 \mathrm{~B}(\mathrm{OH})}=(1.25 \pm 0.20) \times 10^{-12} \exp (612 \pm 50 / \mathrm{T}) \\
& \mathrm{k}_{4 \mathrm{H} 2 \mathrm{~B}(\mathrm{OH})}=(7.5 \pm 2.0) \times 10^{-12} \exp (196 \pm 20 / \mathrm{T})
\end{aligned}
$$

For both reactions, the rate coefficient shows negative temperature dependence. This indicates that the reaction is carried out initially without activation energy barrier. This trend shows that the processes involved in this reaction are a succession of elementary steps involving unstable intermediate complexes.

\subsection{Mechanism and Effect of the structure on the reactivity}

As for other aliphatic ketones or alcohols, the reaction of $3 \mathrm{H} 2 \mathrm{~B}$ and $4 \mathrm{H} 2 \mathrm{~B}$ with $\mathrm{OH}$ radicals and $\mathrm{Cl}$ atoms are expected to proceed mainly by $\mathrm{H}$-abstraction process from different sites as follows:

$$
\mathrm{CH}_{3} \mathrm{C}(\mathrm{O}) \mathrm{CH}(\mathrm{OH}) \mathrm{CH}_{3}+\mathrm{OH} / \mathrm{Cl} \rightarrow \quad{ }^{\circ} \mathrm{CH}_{2} \mathrm{C}(\mathrm{O}) \mathrm{CH}(\mathrm{OH}) \mathrm{CH}_{3}+\mathrm{H}_{2} \mathrm{O} / \mathrm{HCl}
$$


SAR calculations based on the structure / reactivity relationship using AOPWIN model, (AOPWIN, 2000) were done for the reaction of 3H2B with $\mathrm{OH}$. The results estimate that the contribution of each reaction pathway (a), (b), (c) and (d) are respectively $0.5 \%, 2.5 \%, 94 \%$ and $3 \%$.

SAR calculations showed that the contribution of each reaction pathway (e), (f), (g) and (h) for the reaction of $4 \mathrm{H} 2 \mathrm{~B}$ with $\mathrm{OH}$ are respectively: $0.8 \%, 1.2 \%, 92 \%$ and $6 \%$ showing that the reaction of $4 \mathrm{H} 2 \mathrm{~B}$ with $\mathrm{OH}$ radicals proceeds mainly by $\mathrm{H}$-abstraction from the $\mathrm{C}-\mathrm{H}$ bonds in the $\beta$ position to carbonyl group.

The dominant pathways ( $\mathrm{c}$ and $\mathrm{g}$ ) may lead to the formation of dicarbonyl products such as 2,3-butanedione from the oxidation of 3H2B with $\mathrm{OH}$ and 3-oxobutanal from the oxidation of $4 \mathrm{H} 2 \mathrm{~B}$ with $\mathrm{OH}$. For the reaction with $\mathrm{Cl}$ atoms, chlorine atoms are less selective than $\mathrm{OH}$ radicals and the contribution of $\mathrm{H}$-atom abstraction in $\mathrm{Cl}$ atoms would be more spread out than that for $\mathrm{OH}$. Therefore, a mechanistic study would be of great interest in order to facilitate the comprehension of these results.

The $\mathrm{Cl}$ reactivity of the hydroxyketones investigated here is lower by a factor of 1.5 and 3 than that of the corresponding alcohols showing the deactivating effect of the carbonyl group (Table 4). However, no significant effect of the carbonyl group on the reactivity with $\mathrm{OH}$ was observed in comparison between the studied hydoxyketones to the corresponding alcohols (Table 4). Additionally, as for other $\mathrm{C}_{4}$-hydroxyketones studied by Aschmann et al. (2000a), the rate coefficients obtained in this work at $298 \mathrm{~K}$ for reactions with $\mathrm{OH}$ are lower than those for $\mathrm{C}_{5}-\mathrm{C}_{8}$ hydroxyketones (except for 1-hydroxy 4-heptanone). As expected, the comparison shows that the reactivity of these species with $\mathrm{OH}$ increases with the chain length. Until now, there is no study concerning the $\mathrm{Cl}$ reactivity with $\geq \mathrm{C}_{4}$-hydroxyketones. Our values are therefore compared to the rate coefficient of the reaction of hydroxyacetone with $\mathrm{Cl}(5.6 \pm 0.7) \times 10^{-11} \mathrm{~cm}^{3}$ molécule $\mathrm{s}^{-1} \mathrm{~s}^{-1}$ reported by Orlando et al. (1999). This comparison shows an increasing of the reactivity with the carbon chain length. 
The rate coefficients for $3 \mathrm{H} 2 \mathrm{~B}$ and $4 \mathrm{H} 2 \mathrm{~B}$ obtained in this work compared to that of $2-$ 350 butanone $\left(\mathrm{CH}_{3} \mathrm{C}(\mathrm{O}) \mathrm{CH}_{2} \mathrm{CH}_{3}\right)$ suggests that the reactions with $\mathrm{OH}$ proceed via $\mathrm{H}$-abstraction of the weakest $\mathrm{C}-\mathrm{H}$ bond on the $-\mathrm{CH}_{2} \mathrm{OH}$ group activated by the presence of the $-\mathrm{OH}$ substituent group. Further, the position of the hydroxyl group relative to the carbonyl group was found to affect the kinetics of the studied reactions. Indeed, the rate coefficients of the oxidation of 4H2B by $\mathrm{OH}$ are higher than those for $3 \mathrm{H} 2 \mathrm{~B}$. This shows that the carbonyl group deactivate the $\mathrm{H}$-abstraction from the $\mathrm{C}-\mathrm{H}$ bond located in the $\alpha$ position and activate that located in the $\beta$ position.

\section{Atmospheric implication}

The tropospheric lifetimes due to reactions with $\mathrm{OH}$ and $\mathrm{Cl}$ were estimated according to the equation $\tau=1 / k[X]$ where $[X]$ represents the average concentration of the oxidant and $k$ the rate coefficient for the reaction of the studied compounds with the oxidant. The rate coefficients obtained in this work were combined with the average tropospheric concentration of $\mathrm{OH}$ radicals and $\mathrm{Cl}$ atoms to assess the major atmospheric loss process of $3 \mathrm{H} 2 \mathrm{~B}$ and $4 \mathrm{H} 2 \mathrm{~B}$ and their atmospheric lifetimes. The lifetimes were calculated by using 24 hours daytime average global tropospheric concentration of $1 \times 10^{6}$ molecule $\mathrm{cm}^{-3}$ (Atkinson et al., 1997b) and $1 \times 10^{3}$ molecule $\mathrm{cm}^{-3}$ (Singh et al., 1996) for $\mathrm{OH}$ radicals and $\mathrm{Cl}$ atoms respectively.

In the atmosphere, another removal source of the studied compounds can be photodissociation due to sun light. The absorption cross sections of these species have been measured by Messaadia et al. (2012) and their upper limits of photodissociation rate coefficients $\left(\mathrm{J}_{\mathrm{p}}\right)$ have been calculated using their cross section measurements and assuming a quantum yield of unity. Therefore, the calculated lifetimes (see Table 5) have to be considered as lower limits since the photolysis quantum yields could be much lower than unity. The reactivity of $3 \mathrm{H} 2 \mathrm{~B}$ and $4 \mathrm{H} 2 \mathrm{~B}$ towards $\mathrm{NO}_{3}$ radicals and $\mathrm{O}_{3}$ has been investigated by Aschmann et al. (2000a), by using a relative technique. A lower limit of 150 days for the tropospheric lifetime of these species due to their reaction with $\mathrm{O}_{3}$ is reported. This shows that the contribution of the reaction with $\mathrm{O}_{3}$ in the atmospheric fate of the studied compounds is negligible. In Table 5, the lifetimes of 3H2B and 4H2B due to $\mathrm{OH}$ and $\mathrm{Cl}$ calculated in this work are compared to those due to $\mathrm{NO}_{3}$ and $\mathrm{O}_{3}$ and photolysis.

The obtained lifetimes of $3 \mathrm{H} 2 \mathrm{~B}$ and $4 \mathrm{H} 2 \mathrm{~B}$ due to reactions with $\mathrm{OH}$ ( $\sim 1$ day) indicate that the gas-phase reaction with the $\mathrm{OH}$ will dominate over the other chemical processes. Photolysis seems to be an important loss process for $3 \mathrm{H} 2 \mathrm{~B}$ and $4 \mathrm{H} 2 \mathrm{~B}$ provided that the assumption with respect to the quantum yield is correct, and then it could be more important 
than the degradation by chemical reactions. However, the reactions with $\mathrm{Cl}$ atoms could be an important loss process for these species in coastal areas where the concentration of $\mathrm{Cl}$ atoms reaches $1 \times 10^{5}$ molecule $\mathrm{cm}^{-3}$ (Spicer et al., 1998).

\section{Conclusion}

The kinetics of the reaction of 3-hydroxy-2-butanone and 4-hydroxy-2-butanone with respect to reaction with $\mathrm{OH}$ radicals and $\mathrm{Cl}$ atoms was investigated using relative method. The obtained data showed that the reaction of the studied compounds with $\mathrm{Cl}$ atoms proceeds more rapidly than that with $\mathrm{OH}$ radicals. The reactivity of these species was found to be sensitive to the structure of hydroxyketones and to be activated by the presence of the hydroxyl group. Slight negative temperature dependence was observed for the reactions of $3 \mathrm{H} 2 \mathrm{~B}$ and $4 \mathrm{H} 2 \mathrm{~B}$ with $\mathrm{OH}$ showing that the processes involved in these reactions are a succession of elementary steps involving unstable intermediate complexes.

The atmospheric lifetimes of the studied compounds were calculated with respect to $\mathrm{OH}$ and $\mathrm{Cl}$ using rate coefficients at room temperature obtained in this work. The calculated tropospheric lifetime suggests that once emitted into the atmosphere, 3H2B and 4H2B can be degraded quite rapidly ( 1 day) and thus contribute to the photochemical pollution in a local or regional scale.

This work represents the first reported kinetic study of the reaction of $\mathrm{OH}$ radicals with hydroxyketones as a function of temperature and the first kinetic study of the reaction of $\mathrm{Cl}$ with these species ever obtained. However, a detailed mechanistic study of the reaction with $\mathrm{OH}$ radicals and $\mathrm{Cl}$ atoms is required to provide a much improved understanding of the mechanism of the reaction of $\mathrm{OH}$ and $\mathrm{Cl}$ with hydroxyketones and the temperature dependence.

\section{Acknowledgements}

The authors gratefully thank the INSU-LEFE program, Eurochamp 2 EU project and the Labex Voltaire (ANR-10-LABX-100-01)

\section{References}

Anderson, R.S., Huang, L., Iannone, R., Rudolph J., 2007. Measurements of the 12C/13C kinetic isotope effects in the gas-phase reactions of light alkanes with chlorine atoms. Journal of Physical Chemistry A 111, $495-504$. 
AOPWIN, 2000. Atmospheric Oxidation Program for Microsoft Windows . Version 1.92. U.S. Environmental Protection Agency.

Atkinson, R., Baulch, D.L., Cox, R.A., Hampson, R.F., Kerr, J.A., Rossi, M.J., Troe, J., 1997b. Evaluated kinetic and photochemical data for atmospheric chemistry: Supplement VI IUPAC subcommittee on gas kinetic data evaluation for atmospheric chemistry. Journal of physical and Chemical Reference data 26, 1329 - 1499

Atkinson, R., Aschmann, S.M., Arey, J., 2008. Atmospheric chemistry of alkanes: Review and recent Developments. Atmospheric Environment 42, 5859-5871

Baker, J., Arey, J., Atkinson, R., 2004. Journal of Physical Chemistry A 108, 7032 - 7037

Ballesteros, B., Garzon, A., Jiménez, E., Notario, A., Albaladejo, J., 2007. Relative and absolute kinetic studies of 2-butanol, and related alcohols with tropospheric $\mathrm{Cl}$ atoms. Physical Chemistry Chemical Physics 9, 1210-1218.

Bethel, H. L., Atkinson, R., Arey, J., 2001. International Journal of Chemical Kinetics 33, 310 $-316$.

Bethel, H.L., Atkinson, R., Arey, R.J., 2003. Journal of Physical Chemistry A 107, 6200.

DECHEMA. DETHERM Chemical Database Online. www.dechema.de Dykyi, J.and M. Repas. "Saturation Vapor Pressure of Organic Compounds." Veda Vydavatelstvo Slovenskej Akademie Vied, Bratislava, 1979.

El Dib, G., Sleiman, C., Canosa, A., Travers, D., Courbe, J., Sawaya, T., Mokbel, I., Chakir, A., 2013. Journal of Physical Chemistry A 117, 117-125.

Ichikawa, N., Sato, S., Takahashi, R., Sodesawa, T., 2005. Synthesis of 3-buten-2-one from 4hydroxy-2-butanone over anatase-TiO2 catalyst. Catalysis Communications 6, 19-22.

IUPAC database, Subcommittee on gas kinetic data evaluation. http://www.iupackinetic.ch.cam.ac.uk/

Messaadia, L., El Dib, G., Ferhati, A., Roth, E., Chakir, A., 2012. Chemical Physics letters $529,16-22$.

Notario., Le Bras G., Mellouki A., 1998. Absolute rate constants for reactions of $\mathrm{Cl}$ atoms with a series of esters. The Journal of Physical Chemistry A 102, 3112-311. 
Orlando, J., Tyndall, G., Fracheboud, J.M., Estupin, E.G., Haberkorn, S., Zimmer, A., 1999. Atmospheric Environment 33,1621.

Rivas B., Torre P., Dominguez J . M., Perego P., Converti, A., Parajo J.C., 2003. Carbon material and bioenergetic balances of xylitol production from corncobs by Debaryomyces.hansenii. Biotechnololy Progress 19, 706-13.

Sauer, C.G., Barnes, I., Becker, K.H., Geiger, H., Wallington, T.J., Christensen, L.K., Platz, J., Nielsen, O.J., 1999. Atmospheric Chemistry of 1,3-Dioxolane: Kinetic, Mechanistic, and Modeling Study of OH Radical Initiated Oxidation. The Journal of Physical Chemistry A $103,30,5959-5966$.

Semadeni, M., Stocker, D.W., Kerr, J.A., 1995. The temperature dependence of the OH radical reactions with some aromatic compounds under simulated tropospheric conditions. International Journal of Chemical Kinetics 27, 287-304.

Singh H. B.; Thakur A. N., Chen Y. E. y Kanakidou M., 1996. Tetrachloroethylene as an Indicator of low $\mathrm{Cl}$ Atom Concentrations in the Troposphere. Geophysical Research Letter, $23,1529-1532$.

Spicer, C.W., Chapman, E.G., Finlayson-Pitts, B.J., Plastridge, R.A., Hubbe, J.M., Fast, J.D., Berkowitz, C.M., 1998. Unexpectedly high concentrations of molecular chlorine in coastal air. Nature 394, 353-356.

Thevenet R., Mellouki A., Le Bras G., 2000. Kinetics of $\mathrm{OH}$ and $\mathrm{Cl}$ Reactions with a Series of Aldehydes, International Journal of Chemical Kinetics, 32, 676-685. 